\title{
How uniform is donor history questionnaire for screening potential blood donors: a critical analysis
}

\author{
Jayant Kumar Kairi, Manmeet Kaur*
}

Department of Pharmacology, Kalpana Chawla Government Medical College, Karnal, Haryana, India

Received: 05 February 2021

Revised: 11 March 2021

Accepted: 12 March 2021

\section{*Correspondence:}

Dr. Manmeet Kaur,

Email: drmanmeet26@hotmail.com

Copyright: (C) the author(s), publisher and licensee Medip Academy. This is an open-access article distributed under the terms of the Creative Commons Attribution Non-Commercial License, which permits unrestricted non-commercial use, distribution, and reproduction in any medium, provided the original work is properly cited.

\begin{abstract}
Background: Transfusion of whole blood or blood products are a clinical necessity in numerous clinical conditions. Blood donated from healthy human volunteers is the only method currently available to acquire blood transfusion and production of blood products. Donor history questionnaire (DHQ) contributes immensely to ensure safe blood donation. The aim was to compare the donor history questionnaire for blood donation deferral of various regions and organizations with that of World Health Organization (WHO).

Methods: An extensive internet search for donor history questionnaires (DHQ) for blood donation deferral of different regions, countries and organization was conducted. Seven such forms were found which could be downloaded. A critical analysis of these forms was conducted based on history pertaining to use of medicines, disease history or procedure undergone recently. A comparative analysis was conducted finally with the World Health Organization (WHO) recommendations on the issue of donor screening and deferral. Descriptive analysis was done for comparison of donor history questionnaires in regards to drugs taken, disease history and invasive procedures performed.

Results: After the analysis of the DHQs, we found that despite many similarities, there were significant differences in the questionnaires. The differences were more with respect to questions asked about the medicines, both traditional as well as modern.

Conclusions: DHQs analysed by us revealed wide variations in their enquiry from potential donors about exposure to prescription medicines as well as the disease history. A suggestion is that more questions related to alternative medicines, nutraceuticals and other similar xenobiotic should be included.
\end{abstract}

Keywords: Blood donors, Donor history questionnaires, Drugs, Medication

\section{INTRODUCTION}

Blood or blood products are needed for replacement in numerous clinical conditions. Many of these conditions are life threatening and hence the transfusion is conducted in emergency. ${ }^{1}$ Blood donated from healthy human volunteers in the only method currently available to acquire blood for transfusion and production of blood products. ${ }^{2}$ However, transfusion of blood and its products are not without risks. In fact, a poorly acquired and transfused blood may do more harm than good defeating the therapeutic aim. It was realized quite early that blood from every donor might not be fit for transfusion. Much of the unsuitability of donated blood for transfusion is related to transfusion related infection (TTI). Naturally, there is a lot of emphasis to prevent TTIs to the recipients. ${ }^{3}$

The focus of donor selection is to select a donor in good health. Such health may have been achieved with the use of prescribed medicines for whatever chronic ailments they might be having. Barring a few medicines, most medicines are not known to cause drastic effect on transfusible blood. ${ }^{4}$ What is not clearly known that how many amongst the large group of over-the-counter 
medicines affect the suitability of blood collected for transfusion? The donors may not even remember the usage of these medications unless information is sought specifically. Donor questionnaires seeking information from potential donors to determine the suitability of using their donated blood is a time tested way of carrying out this task. There was considerable lack of clarity and direction in what should be the content of the questionnaire to make it reliable, usable and acceptable universally. Back in 2005 , the WHO had stepped in to provide a lead in this regard. Over a period of several years if has refined the advisory and the document is hosted on WHO website. The document prepared by the WHO is quite exhaustive and for most of the conclusions drawn, status of evidence has been provided. The same document suggests the member nations to develop their own donor screening questionnaires. ${ }^{5}$ It is difficult, if not impossible, to reliably determine, exactly how many member nations of WHO have a blood donor-screening questionnaire that is universally being used in that nation. Through an internet search, the authors analysed seven such questionnaires in public domain used by nations or large organizations.

Since the clinical indications of blood transfusion are same world over and human blood is same in its components with minor variations, it is assumed that the donor screening will be uniform or very similar to meet the objectives of collecting the safest blood possible for transfusion purposes. Interestingly, we noted that despite broad concurrence in the information sought from potential donors there were considerable differences too. In view of this finding, the authors analysed these seven questionnaires to document differences and draw meaningful conclusions if any.

\section{METHODS}

This was a web based search was conducted to find out the authentic donor history questionnaires of different regions across the world and organization. This web based search for the questionnaire was done in October-November 2018.

After extensive search, the questionnaires of Hong Kong, the Red Cross Service, Ireland, Singapore, Canada, Western Province of South Africa, National AIDS Control Organization (NACO) and Red Cross Organization that were available online were selected for comparison. ${ }^{6-11} \mathrm{~A}$ few more DHQs were available on the internet in the form of web pages running through multiple sections making them difficult to compare. Hence, only those DHQs were selected that we were able to download and print. The questionnaires were then evaluated based on questions asked about history related to medicine use, disease conditions and the interventional procedures that the potential donors might have had in the past. The questionnaires are hosted on web pages in public domain and mention no copyright or any other restrictions. Since this study is related to humans but not on human beings, it does not mandate any clearance from Ethics Committee. The history of medications sought is categorized based on pharmacological drug class for easier tabulation and presentation. The rest two variables, the history of diseases suffered and procedures undergone have been tabulated in actual numbers. Finally, the three variables have been compared with those mentioned in the suggested WHO questionnaire to understand the variation.

\section{RESULTS}

Recent exposure to NSAIDs would be the commonest medication related reason for donor deferral. All the seven questionnaires analysed, were found unanimous in deferring a potential donor who has had aspirin recently (Table 1). Vitamin A derivatives- isotretinoin and acitretin found significant mention. Isotretinoin however was considered to have much more potential to harm, as six out of seven questionnaires sought information specifically to defer donors exposed to it. Only two questionnaires asked about acitretin. It is noteworthy that both are dermatological drugs and not used systematically. Antiandrogenic drugs, finasteride and dutasteride are also among the prohibited drugs in six out of seven DHQs, making them one of the most important drug related cause of donor deferral. Recent vaccination of any kind or blood transfusion with in a stipulated period will surely lead to deferral of the potential donor. Six of seven DHQs concurred on this issue. Exposure to therapeutic hormones in both males and females will disqualify potential donors as per five out of seven documents examined by us. We could not identify any pattern for most other drug groups such as anti-coagulants, antibiotics, anti-HCV drugs. Persons on any injectable drug were advised to be deferred in half of the DHQs. Anti-D immunoglobulin, vitamins, alcohol and many other substances find sporadic mention in just one out of seven analysed DHQs. The DHQs of Ireland and Red Cross organization came out to be the choosiest regarding drug exposures while NACO (India) appears to be least choosy (Figure 1).

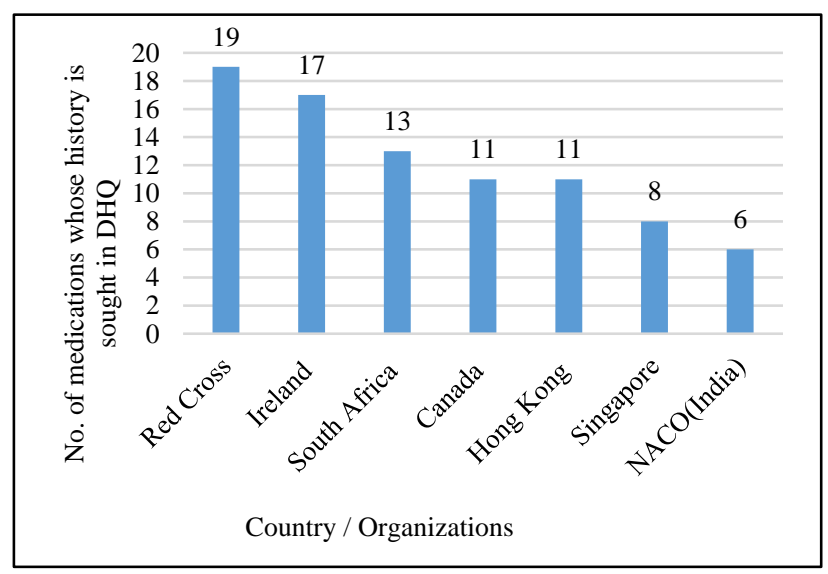

Figure 1: Comparison of number of medications whose history is sought in DHQ by different organizations and countries. 
Table 1: Questionnaires of countries/organizations included in the study.

\begin{tabular}{|c|c|c|c|c|c|c|c|}
\hline $\begin{array}{l}\text { History sought for drug classes in the } \\
\text { questionnaires }\end{array}$ & $\begin{array}{l}\text { Hong } \\
\text { Kong }\end{array}$ & Ireland & South Africa & Canada & Singapore & $\begin{array}{l}\text { NACO } \\
\text { (India) }\end{array}$ & $\begin{array}{l}\text { Red } \\
\text { Cross }\end{array}$ \\
\hline Medications affecting coagulation & & & & & & & \\
\hline Aspirin & \multirow{6}{*}{$5+$} & \multirow{6}{*}{$5+$} & \multirow{6}{*}{$5+$} & \multirow{6}{*}{$4+$} & \multirow{6}{*}{$3+$} & \multirow{6}{*}{$2+$} & \multirow{6}{*}{$5+$} \\
\hline NSAIDS OR related drugs & & & & & & & \\
\hline Antiplatelets & & & & & & & \\
\hline Anticoagulants & & & & & & & \\
\hline Blood products/clotting factors & & & & & & & \\
\hline Blood transfusion & & & & & & & \\
\hline \multicolumn{8}{|l|}{ Hormones and antagonists } \\
\hline Finasteride/dutasteride & \multirow{9}{*}{$5+$} & \multirow{9}{*}{$7+$} & \multirow{9}{*}{$3+$} & \multirow{9}{*}{$3+$} & \multirow{9}{*}{$1+$} & \multirow{9}{*}{$1+$} & \multirow{9}{*}{$6+$} \\
\hline Human growth hormone & & & & & & & \\
\hline Anabolic steroids & & & & & & & \\
\hline Human GN hormone & & & & & & & \\
\hline Insulin & & & & & & & \\
\hline Infertility drugs & & & & & & & \\
\hline Oral contraceptives & & & & & & & \\
\hline Hormone replacement therapy & & & & & & & \\
\hline Any glucocorticoids & & & & & & & \\
\hline \multicolumn{8}{|l|}{ Retinoic acid derivative } \\
\hline Isotretinoin (drug for acne) & \multirow{2}{*}{$1+$} & \multirow{2}{*}{$1+$} & \multirow{2}{*}{$1+$} & \multirow{2}{*}{$2+$} & \multirow{2}{*}{$1+$} & \multirow{2}{*}{0} & \multirow{2}{*}{$2+$} \\
\hline Acitretin & & & & & & & \\
\hline \multicolumn{8}{|l|}{ Immune related } \\
\hline Vaccines & \multirow{3}{*}{0} & \multirow{3}{*}{$2+$} & \multirow{3}{*}{$1+$} & \multirow{3}{*}{$1+$} & & & \\
\hline Anti d immunoglobulin & & & & & $1+$ & $1+$ & $2+$ \\
\hline Immunomodulators & & & & & & & \\
\hline Antimicrobials & & & & & & & \\
\hline Anti HIV & & & & & & & \\
\hline Antibiotics & 0 & $1+$ & $1+$ & 0 & $1+$ & $1+$ & $2+$ \\
\hline Anticancer drugs & & & & & & & \\
\hline Drugs for skin cancer (vismodegib) & 0 & 0 & 0 & 0 & 0 & 0 & $1+$ \\
\hline Other medications/ nutritional suppler & ents & & & & & & \\
\hline Chinese/ traditional medicine & & & & & & & \\
\hline Vitamins & 0 & $1+$ & $2+$ & $1+$ & $1+$ & 1 & $1+$ \\
\hline Alcohol & & & & & & & \\
\hline $\begin{array}{l}\text { Total number of medicines asked } \\
\text { about in the questionnaire }\end{array}$ & 11 & 17 & 13 & 11 & 8 & 6 & 19 \\
\hline
\end{tabular}

(Number in the columns indicate the number of medicines directly asked about from each drug class in the questionnaire)

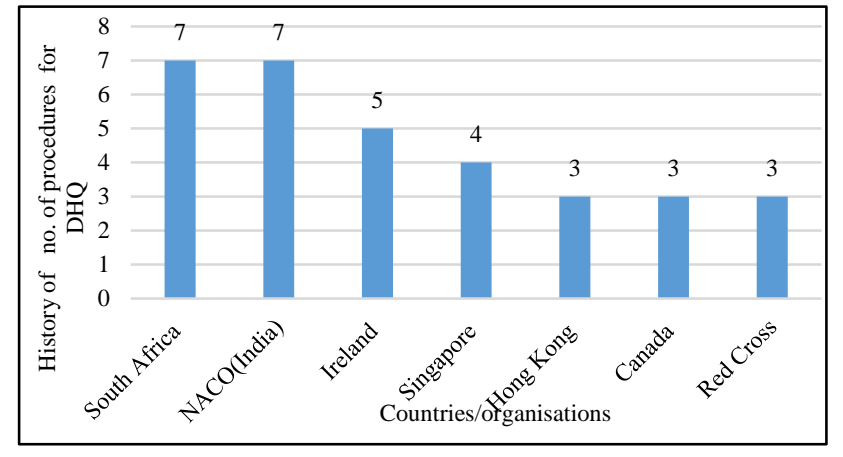

Figure 2: Comparison of number of procedures whose history is sought in DHQ by different organizations and countries.

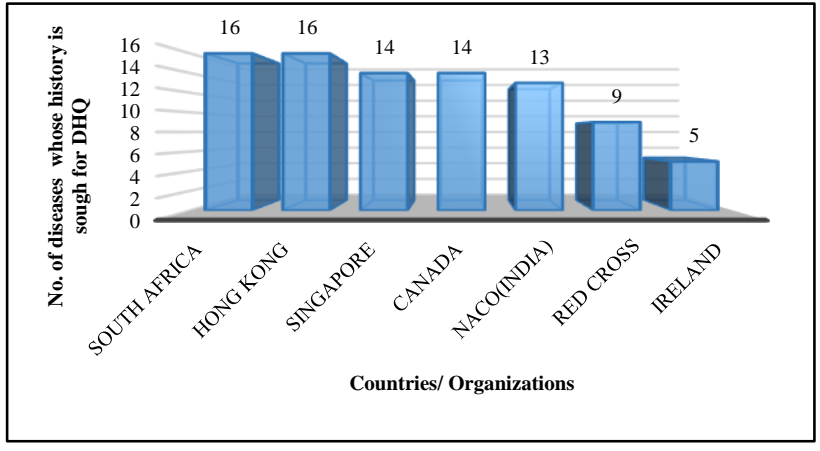

Figure 3: Comparison of number of diseases whose history is sought in DHQ by different organizations and countries. 
On tabulating the DHQ questions on surgical procedures, it is evident that highly invasive treatments such as dental, gastrointestinal instrumentation, kidney procedures, acupuncture, body piercing were considered to have the highest risk. The comparison in terms of procedures enquired about is given in Figure 2. South Africa and NACO appeared to consider surgical procedures more seriously that the rest as they sought history about seven surgical procedures (Figure 2).

Table 2: Comparison of the variables with WHO (suggested) blood donor questionnaire.

\begin{tabular}{|lllllllll|}
$\begin{array}{l}\text { Parameter (n=total } \\
\text { number in document) }\end{array}$ & WHO & Hong Kong & Ireland & Singapore & Canada & $\begin{array}{l}\text { South } \\
\text { Africa }\end{array}$ & $\begin{array}{l}\text { NACO } \\
\text { (India) }\end{array}$ & Red cross \\
\hline Medicines & 9 & 11 & 17 & 8 & 11 & 13 & 6 & 19 \\
\hline Procedures & 11 & 3 & 5 & 4 & 3 & 7 & 7 & 3 \\
Disease conditions & 30 & 16 & 5 & 14 & 14 & 16 & 13 & 9 \\
\hline
\end{tabular}

Amongst the ailments and other medical conditions, cardiovascular, endocrine and metabolic diseases were considered to be noteworthy in all the seven DHQs. Six out of seven of them considered infections such as tuberculosis, hepatitis, sexually transmitted diseases to seriously affect the suitability of donors for donating blood. Hong Kong and Canada DHQs are most scrupulous in their enquiry about history of illness in the potential blood donors with Hong Kong seeking information about 16 conditions. Ireland was least choosy with information asked about only five diseases. The frequency of enquiry about diseases in the DHQs is given in Figure 3.

Table 2 depicts the comparison of the variables with WHO (suggested) blood donor questionnaire.

\section{DISCUSSION}

The need to ensure safe blood for transfusion cannot be emphasized enough. Therefore, the DHQ is expected to be universal and similar in the enquiries that are made to ensure collection of safe blood for transfusion. Our study made an exploratory attempt to compare the WHO suggested DHQ with seven DHQs of countries/ organizations. To the best of the knowledge of the authors, there is no such published comparison. A lot of difference are noted between the WHO list and those being incorporated in the studied DHQs (Table 2).

The WHO advisory is quite exhaustive in terms of the infections that need to be kept in mind while screening the potential donors. There are 9 drugs, 103 diseases, 11 surgical procedures on which the WHO provided technical recommendations and evidence thereof, for deferral. Interestingly, WHO's suggested DHQs has 9 drugs, 30 diseases, 9 procedures. ${ }^{5}$ The DHQs analysed by us have considered 26 medicines, 19 disease conditions, 07 surgical procedures. This finding is significant in concept because the criteria affecting blood collection from donors are universal and hence the measures to ensure safety through DHQs expected to be same or similar. When compared to the WHO document, the DHQs analysed by us mention much less disease condition, while most DHQs have much greater number of medicines for which history has been sought. It is entirely justifiable an understandable that there is great emphasis on drug history. Exposure to medicines in vivo can change the characteristics of the stored blood and the oxygen carrying capacity of the RBCs. ${ }^{12,13}$ There could also be an increase in the osmotic fragility of the RBCs. ${ }^{14}$ Changes in the quality of transfused RBCs can actually affect the therapeutic goal of transfusion. Canadian, Hong Kong and South African DHQs have nearly same number of medications for which history has been sought from potential blood donors. It is felt that in those countries where government control over drug availability is tightly regulated, a reliable history of exposure to medicines can be estimated through other history regarding disease or procedures. However, in countries where accessibility to medicines is easy and without explicit guidance from authorized medical personnel such as third world countries, a more detailed history about medication intake seems reasonable and desirable. Given the unhindered availability of prescription medicines, the chances of self-medication increases many fold. In an era of internet access through hand held devices, self-medication is on the rise. ${ }^{15}$

In such a situation, an accurate estimation of exposure to undesirable medicines in potential blood donors can be achieved only by asking a direct question about the medicines. It is therefore surprising the donor questionnaire of NACO, India has questions only about 6 drugs. The DHQ of Red Cross is found to be most exhaustive in this aspect with as many as 19 drugs for which history has been sought from potential donors.

Notably, out of seven DHQs only two have specific and direct question about alternative medicines. Singapore DHQ has a question about use of Chinese medicines that is understandable due to its native population. Surprisingly, the NACO of India has not asked about traditional medicines especially Ayurveda. There is a resurgent interest in Ayurveda in India and world over due to a significant impetus provided by the central government to all traditional or alternative medical streams under the name of AYUSH (Ayurveda, Yoga and Naturopathy, Unani, Siddha and Homeopathy). Ayurveda dominates the arena of AYUSH in India as it has a very 
wide number of medicines and formulations. Many of these formulations contain heavy metals also. ${ }^{16}$ Heavy metals are known to affect RBC fragility in vitro and in vivo. ${ }^{17}$ Therefore, specific enquiries about alternative medicines in DHQs would be appropriate. This is considered necessary, because there are not many studies that have studied the effect of alternative medicines on the quality of stored blood or blood products.

South Africa and Hong Kong have asked maximum number of questions to their potential blood donors about history of previous diseases in contrast to Red Cross which seems to be enquiring much less about this issue. This finding indirectly co-relates with their direct enquiry about medicines. This finding also strengthens our view that the Red Cross which operates all over the world and most of conflict prone areas are in the Third World countries with poor government regulation of prescription medicines, direct enquiry is probably more reliable.

Therefore, the NACO document could include some more direct questions about exposure to medicines in potential blood donors. As far as surgical procedures are concerned, there is much greater reliability from the history because most such procedures will involve use of analgesics, with or without antibiotics. Hence, with the exception of DHQ of South Africa and NACO rest six have enquiries limited to 3-4 procedures whereas WHO suggests eleven.

\section{Limitations}

There was no human involvement in the study. It was just a comparison of the online available questionnaire.

\section{CONCLUSION}

To conclude, the DHQs analysed by us revealed wide variations in their enquiry from potential donors about exposure to prescription medicines. More questions related to alternative medicines, nutraceuticals and other similar xenobiotic should be included. The number of DHQs are only seven, which is also the limitation of our rather unique study. It is possible that the blood banks of large hospitals all over the world are using different DHQs, which might be hosted on their respective websites. It was beyond the scope of our study to identity all such DHQs.

Funding: No funding sources

Conflict of interest: None declared

Ethical approval: The study was approved by the Institutional Ethics Committee

\section{REFERENCES}

1. National Blood Policy 2007. New Delhi; National AIDS Control Organization. Ministry of Health and Family Welfare, Government of India. New Delhi cited 2020 Nov Available at: http://www.naco.gov.in/sites/default/files/National\%
20Blood\%20Policy_0.pdf. Accessed on 1 November 2020.

2. Alayash AI. Blood substitutes: why haven't we been more successful? Trends Biotechnol. 2014;32(4):17785.

3. Newman B. Blood donor suitability and allogeneic whole blood donation. Transfus Med Rev. 2001;15:234-44.

4. Bashawri LA. A review of predonation blood donor deferrals in a university hospital. J Fam Community Med. 2005;12(2):79-84.

5. World Health Organization. 2012. Blood donor selection: guidelines on assessing donor suitability for blood donation. World Health Organization. Available from: https://apps.who.int/iris/handle/10665/76724. Accessed on 1 November 2020.

6. Hong Kong Red Cross Blood Transfusion Service. Hong Kong. Available from: https://www5.ha.org.hk/rcbts/don-reg-form. Accessed on 1 November 2020.

7. Irish Blood Transfusion Service. Ireland. Pre Donation Questionnaire. Available from: https://www.giveblood.ie/Can-I-Give-Blood/Predonation-Donor-Questionnaire. Accessed on 1 November 2020.

8. Western Cape Blood Service. South Africa. Confidential Donor Questionnaire. Available from: http://www.wcbs.org.za/wpcontent/uploads/2020/08/WCBS-DQ-Eng-2020-0623-web.pdf. Accessed on 1 November 2020.

9. Canadian Blood Service. Canada. Donor Questionnaire. Available from: https://www.blood.ca/en/blood/donatingblood/donor-questionnaire. Accessed on 1 November 2020.

10. HAS, A Singapore Government Agency Website. Singapore. Available from: https://www.hsa.gov.sg/blood-donation. Accessed on 1 November 2020.

11. American Red Cross Blood Service. 2020 The American National Red Cross. Available from: https://www.redcrossblood.org/donate-blood/how-todonate/eligibility-requirements.html. Accessed on 1 November 2020.

12. Stichtenoth DO, Deicher HR, Frölich JC. Blood donors on medication. Are deferral periods necessary? Eur J Clin Pharmacol. 2001;57(6-7):433-40.

13. Becker CD, Stichtenoth DO, Wichmann MG, Schaefer C, Szinicz L. Blood donors on medication - an approach to minimize drug burden for recipients of blood products and to limit deferral of donors. Transfus Med Hemother. 2009;36(2):107-13.

14. Mustafa I, Al Marwani A, Mamdouh Nasr K, Abdulla Kano N, Hadwan T. Time dependent assessment of morphological changes: leuko depleted packed red blood cells stored in SAGM. Biomed Res Int. 2016;4529434

15. Araia ZZ, Gebregziabher K, Mesfun AB. Selfmedication practice and associated factors among students of Asmara College of Health Sciences, 
Eritrea: a cross sectional study. J Pharm Policy Pract. 2019;12,(3).

16. Galib, Barve M, Mashru M, Jagtap C, Patgiri BJ, Prajapati PK. Therapeutic potentials of metals in ancient India: a review through Charaka Samhita. J Ayurveda Integr Med. 2011;2(2):55-63.

17. Karai I, Fukumoto K, Kageyama K, Horiguchi S. Effect of lead in vitro on water metabolism and osmotic fragility of human erythrocytes. Br J Ind Med. 1982;39(3):295-9.

Cite this article as: Kairi JK, Kaur M. How uniform is donor history questionnaire for screening potential blood donors: a critical analysis. Int J Basic Clin Pharmacol 2021;10:409-14. 